Article

\title{
Effect of Backsheet Properties on PV Encapsulant Degradation during Combined Accelerated Aging Tests
}

\author{
Djamel Eddine Mansour $\left.{ }^{1,2} \mathbb{(}\right)$, Chiara Barretta ${ }^{3}\left(\mathbb{D}\right.$, Luciana Pitta Bauermann $^{1}{ }^{1}$, \\ Gernot Oreski $^{3}{ }^{\circledR}$, Andreas Schueler ${ }^{2}$, Daniel Philipp ${ }^{1}$ and Paul Gebhardt ${ }^{1, *(1)}$ \\ 1 Fraunhofer Institute for Solar Energy Systems ISE, 79110 Freiburg im Breisgau, Germany; \\ djamel.eddine.mansour@ise.fraunhofer.de (D.E.M.); luciana.pitta.bauermann@ise.fraunhofer.de (L.P.B.); \\ daniel.philipp@ise.fraunhofer.de (D.P.) \\ 2 EPFL VPRHO DSPS COSEC-ENAC, CH-1015 Lausanne, Switzerland; andreas.schueler@epfl.ch \\ 3 Polymer Competence Center Leoben GmbH, AT-8700 Leoben, Austria; Chiara.Barretta@pccl.at (C.B.); \\ gernot.oreski@pccl.at (G.O.) \\ * Correspondence: paul.gebhardt@ise.fraunhofer.de
}

Received: 3 June 2020; Accepted: 24 June 2020; Published: 26 June 2020

\begin{abstract}
Long-term photovoltaic (PV) module reliability is highly determined by the durability of the polymeric components (backsheet and encapsulation materials). This paper presents the result of experiments on encapsulant degradation influenced by the backsheet permeation properties. Towards this goal, one type of ethylene/vinyl acetate copolymer (EVA) was aged in glass/EVA/backsheet laminates in accelerated aging tests (up to $4000 \mathrm{~h}$ for Damp-Heat (DH) and up to $480 \mathrm{kWh} / \mathrm{m}^{2}$ for UV and UV-DH combined). The samples contained three backsheets with different permeation properties to examine their impact on EVA degradation. Thermal and chemical characterization shows that the EVA degradation is stronger with the glass-EVA-polyamide (PA)-based backsheet than with the polyethylene terephthalate (PET)-based backsheets. The higher oxygen transmission rate (OTR) of the PA-based backsheet may increase photo-oxidation and aggravating the degradation of EVA in the laminates. Furthermore, FTIR results were used to demonstrate the effect of damp heat exposure on the EVA interfaces, showing an accelerated degradation at the glass-EVA interface. The comparison of accelerated aging stress factors reveals that EVA suffers the strongest chemical and optical degradation when high UV, high temperature and high relative humidity are combined simultaneously.
\end{abstract}

Keywords: encapsulant; backsheet; degradation; accelerated aging; damp-heat; ultraviolet (UV), UV-DH combined; material combination; photovoltaic (PV) module

\section{Introduction}

Photovoltaic (PV) modules are multi-layer structured devices in which the solar cells and circuitry are embedded in transparent polymeric encapsulants materials. These materials are further laminated between glass or polymeric backsheets for additional protection. A careful combination of materials is employed to ensure a service lifetime of 25-30 years: To reach a long-term reliability of PV modules, it is important that each layer retains its properties and functionality over the module lifetime. Aging of polymeric materials will occur to some degree-regardless of the selected weathering conditions. Indoors tests or outdoors aging factors (e.g., ultraviolet (UV), temperature, relative humidity (RH) and their combinations) will set in motion a series of processes that leads to degradation. It has been reported that several PV degradation processes are associated with polymer degradation: Discoloration of encapsulants [1,2] and backsheets [3], backsheet cracking and chalking [4,5], and delamination [6-8]. It is therefore critical to understand which aging factor(s) influence the polymer degradation and 
to what extent. Especially, micro-climatic conditions and load parameters play important roles in polymer degradation.

It has previously been found that small molecules, such as water vapor and oxygen, permeate through the backsheet and initiate degradation processes inside the PV modules [9-13]. The ingress of such gases is governed by the permeation properties of the polymeric backsheets and/or encapsulation materials used. Significant permeation backsheet selectivity has been observed [13]. More precisely, backsheets with a PET (poly-ethylene-terephthalate)-core layer represent a relatively strong barrier against oxygen and acetic acid permeations. In contrast to that, PA (poly-amide) core layer backsheets have much higher oxygen and acetic acid transmission rates (OTR and AATR) at the beginning of the module lifetime $[12,13]$. A correlation between the aging behavior of the backsheets and the electrical performances of PV modules has been reported [14]. These results raise the question of how the backsheet permeation properties affect other PV module components, such as the commonly used encapsulant ethylene vinyl acetate (EVA).

Different EVA degradation processes have been proposed: via thermal oxidation under damp-heat (DH) aging [15-20] or via the chain-scission mechanism provoked by EVA photo-degradation under UV irradiation [21-24]. The effect of different microclimates on the aging behavior of the encapsulant has been studied [25]. Nevertheless, the reason for differences in the degradation of EVA in the most predominant aging tests DH and UV remain to be clarified. Additionally, a recent study of combined accelerated aging tests has drawn attention [26]. The results of most studies indicate that despite the investigation of EVA degradation using Fourier Transform Infra-Red spectroscopy (FTIR-ATR) [17-20,24,25,27], Raman spectroscopy [25,28], Differential Scanning Calorimetry (DSC) $[15,22,24,25,29-36]$ and tensile tests [24,37], the correlation of EVA chemical and thermal properties with stress factor changes remains unclear.

One main objective of this article is to describe the effect of the backsheet's permeation properties on the encapsulant degradation. To this end, different backsheets were used to understand their influence on different encapsulant degradation processes. Subsequently, chemical, thermal and optical characterization methods were used to detect and understand the degradation of the encapsulant caused by applying both dry-UV and DH aging tests separately and simultaneously.

\section{Materials and Methods}

\subsection{Samples and Weathering Tests}

Three different types of commercially available backsheets (BS) were used in PV laminates $\left(18 \times 18 \mathrm{~cm}^{2}\right)$, to understand the influence of material combination on PV polymer degradation. These laminates were prepared by adding to each BS two layers of the same EVA (Specialized Technology Resources) roll, as encapsulant and a transparent solar glass cover (as illustrated in Figure 1) in one lamination run using a Meier vacuum laminator.

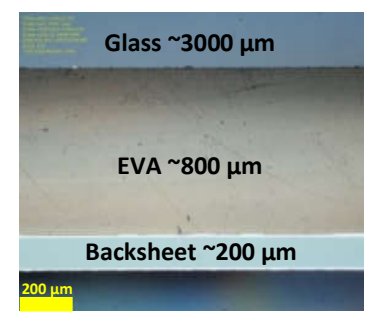

Figure 1. Digital microscopy image of the cross-section to illustrate the sample's structure after lamination.

The samples were then subjected to indoor accelerated aging tests under the (1) DH tests in time intervals of $500 \mathrm{~h}$ (Step 1) up to $4000 \mathrm{~h}$ (Step 8), (2) dry-UV irradiation tests in intervals of 60 $\mathrm{kWh} / \mathrm{m}^{2}$ (Step 1) up to a total irradiation of $480 \mathrm{kWh} / \mathrm{m}^{2}$ (Step 8). Both DH (1) and dry-UV (2) tests are based on the International Electrotechnical Commission (IEC) standard IEC61215:2016 [38] and (3) a 
combined UV-DH (air $60^{\circ} \mathrm{C} / 85 \% \mathrm{RH}$ ) test with the same varying aging intervals as for the dry-UV tests. This combined test (3) aims at a more realistic representation of degradation by simulating multiple factors simultaneously, where the UV irradiation is comparable to the dry UV test using the same type of UV fluorescence tubes. A summary of materials and aging conditions can be seen in Table 1.

Table 1. Summary of sample configuration and aging conditions.

\begin{tabular}{cccc}
\hline Backsheet Type & $\begin{array}{c}\text { Total DH Duration (1) } \\
\text { [h] (Step 8) }\end{array}$ & $\begin{array}{c}\text { Total Irradiation Dose (2) } \\
{\left[\mathbf{k W h} / \mathbf{m}^{2}\right] \text { (Step 8) }}\end{array}$ & $\begin{array}{c}\text { Total Irradiation Dose-DH (3) } \\
{\left[\mathbf{k W h} / \mathbf{m}^{2}\right] \text { (Step 8) }}\end{array}$ \\
\hline PET-based BS_1 & 4000 & - & 480 \\
PET-based BS_2 & 4000 & 480 & 480 \\
PA-based BS & 4000 & - & 480 \\
\hline
\end{tabular}

\subsection{ATR-FTIR Spectroscopy}

Changes in the chemical composition (e.g., functional group) of EVA surfaces (at glass interface by peeling off the polymer film and at BS interface by peeling off the EVA) were investigated using FTIR Spectroscopy by monitoring the appearance or disappearance of functional groups using a PerkinElmer Spectrometer equipped with a Diamond crystal detector in Attenuated Total Reflection mode. The Evaluated spectral range of $4000 \mathrm{~cm}^{-1}$ to $750 \mathrm{~cm}^{-1}$ was an average of three duplicates for each sample.

\subsection{Raman Spectroscopy}

After each aging step, the laminated samples were measured non-destructively through the glass using a Raman microscope WiTec Alpha 500 to determine the change in fluorescence background intensity caused by EVA degradation. A green laser with a monochromatic wavelength of $532 \mathrm{~nm}$ was used for all samples as an excitation source within a Raman shift range from $0 \mathrm{~cm}^{-1}$ to $3800 \mathrm{~cm}^{-1}$.

\subsection{Yellowness Index}

As a non-destructive technique, optical changes were monitored by means of spectral reflectance measurements with a portable ColorLite sph900 spectrophotometer. The measurements were performed according to standard EN ISE 11664-4, using the CIE $\mathrm{L}^{*} \mathrm{a}^{*} \mathrm{~b}$ color scale and calculated values for yellowness index $(\mathrm{YI})$.

\subsection{Differential Scanning Calorimetry}

Changes in the melting enthalpy and temperature as well as crystallization behavior of the EVA bulk were monitored by means of DSC before and after the exposure to accelerated aging tests. The characterization was performed on a TA Instruments DSC Q200 system. The EVA layers were extracted from the laminates and prepared as $\sim 500 \mu \mathrm{m}$-thick circular discs and placed in an Al crucible. At least 5 samples per aging step were used and averaged. Thermograms were recorded under constant nitrogen flow and at a heating rate of $10^{\circ} \mathrm{C} / \mathrm{min}$ using three temperature evolution phases: (1) a first heating phase from $-40^{\circ} \mathrm{C}$ to typically $180^{\circ} \mathrm{C}$ (2) a cooling phase to $-40^{\circ} \mathrm{C}$ and (3) a second heating phase from $-40^{\circ} \mathrm{C}$ to $180^{\circ} \mathrm{C}$ to identify the reversible processes.

\section{Results and Discussion}

\subsection{Backsheet Comparison: Analysis of EVA Decomposition}

One approach of this study was to analyze the chemical changes of the EVA due to the influence of different backsheet properties. Towards this goal, a comparative analysis of the state of degradation after DH exposure (Test (1) in Table 1) was undertaken using FTIR-ATR spectroscopy. Since the latter is a surface characterization method with a penetration depth of only a few $\mu \mathrm{m}$, EVA samples were 
pressed on the surface facing the glass side (opposite from the backsheet layer) after peeling off the polymer film from the glass (see Figure 2).
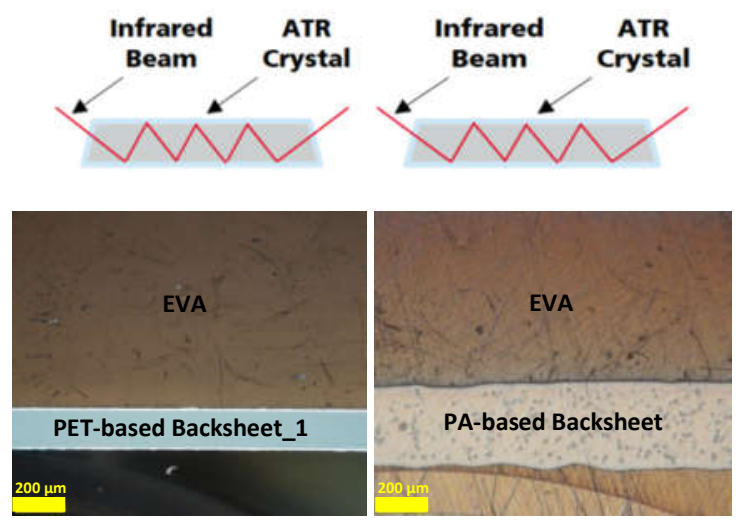

Figure 2. Digital microscopy images of the sample cross-sections to illustrate the sample's structure during FTIR measurements using an attenuated total reflectance mode (ATR) crystal on the EVA surface (glass/EVA) interface.

All expected peaks for intact EVA, representing ethylene and vinyl acetate (VAc) segments were observed in the spectra, as shown in Figure 3, including the different aliphatic $\mathrm{CH}_{\mathrm{x}}$ vibrations (continuous arrows) and the characteristic $\mathrm{C}-\mathrm{O}, \mathrm{C}=\mathrm{O}$ bands (dashed arrows), respectively. Using both PET-based BSs, two noticeable new peaks at $744 \mathrm{~cm}^{-1}$ and $829 \mathrm{~cm}^{-1}$ on the EVA surface start to appear after $1500 \mathrm{~h} \mathrm{DH}$ aging (Figure 3a,b and Table 2). These peaks can be associated with di- and tri-alkyl substance patterns which can be responsible for the yellowing of EVA via additive degradation [17].
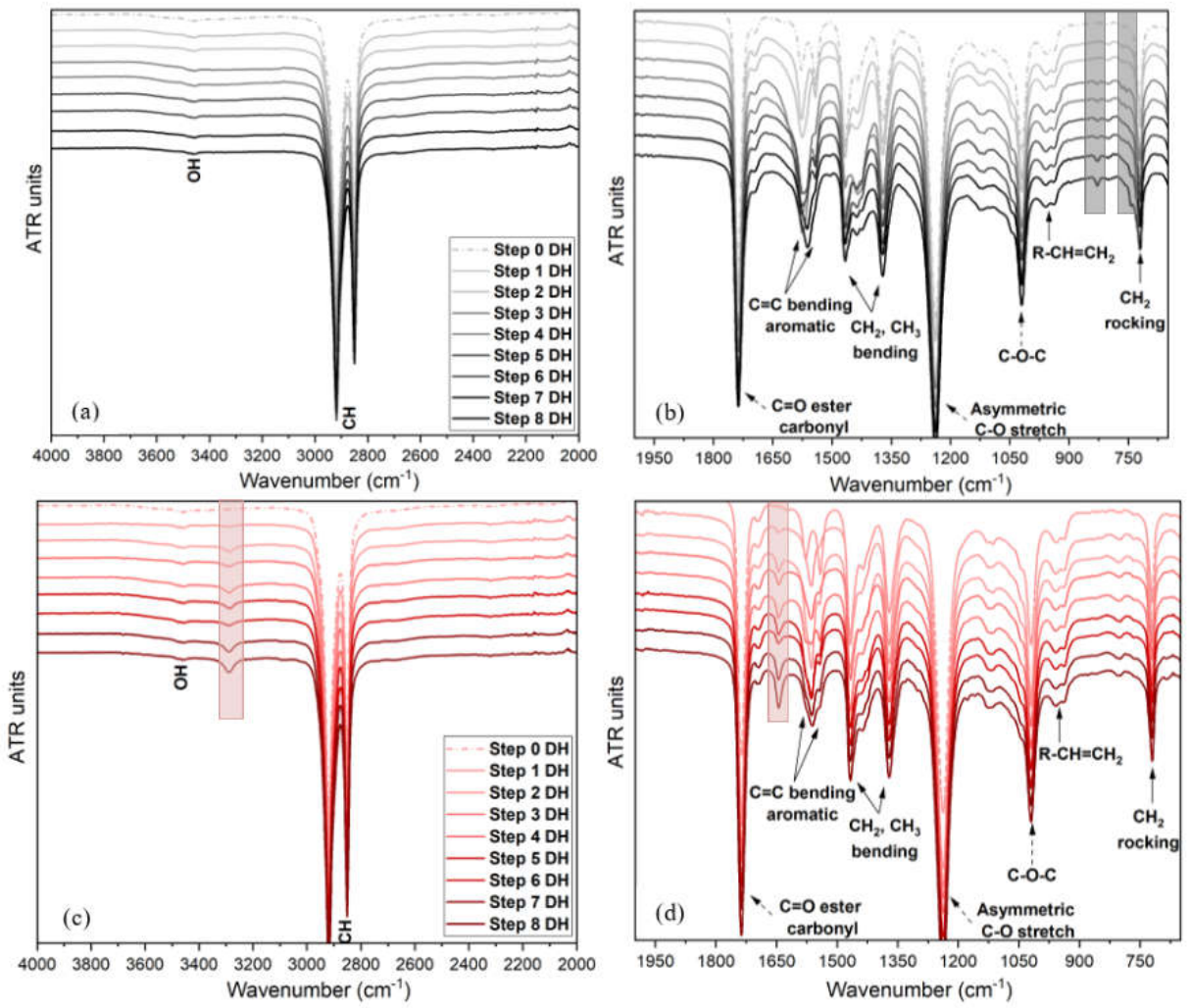

Figure 3. ATR-FTIR spectra of the EVA encapsulant at the glass interface before and after damp heat tests (DH) with PET-based BS_1 in (a,b) and PA-based BS in (c,d). All curves are offset in the y direction for clarity. 
Table 2. FTIR absorption bands undergoing change in ethylene/vinyl acetate copolymer (EVA) from Figure 3.

\begin{tabular}{|c|c|c|}
\hline IR $\left[\mathrm{cm}^{-1}\right]$ & Group & Remark \\
\hline 744 & Diene & CH out-of-plane def. vib. \\
\hline 829 & $\mathrm{R}^{1} \mathrm{R}^{2} \mathrm{C}=\mathrm{CHR} \mathrm{R}^{3}$ & CH out-of-plane bending \\
\hline 1642 & Unsaturated esters & double bonds of a vinyl group \\
\hline 3281 & Hydroxyl & Oxidation products \\
\hline
\end{tabular}

In contrast, when using PA-based BS, the FTIR spectrum of the EVA surface exhibits a narrowing of the peaks at $1642 \mathrm{~cm}^{-1}$ and $3281 \mathrm{~cm}^{-1}$ after the first DH test interval $(500 \mathrm{~h})$, as shown in Figure $3 \mathrm{c}, \mathrm{d}$. The peak at $1642 \mathrm{~cm}^{-1}$ corresponds to a ketone band shift which is consistent with the formation of unsaturated carbonyl products. In parallel, hydroxyl formation is also observed at $3281 \mathrm{~cm}^{-1}$ (Table 2). These degradation products may be formed by the breakdown of hydroperoxides. Alternatively, they could also be derived from the decomposition of additives whose initial components cannot be detected in the FTIR. In this case, the EVA spectral changes are consistent with thermal oxidative degradation processes [39-41].

\subsection{Interface Comparison: Analysis of EVA Decomposition}

In addition to the comparison of the backsheet influence, the purpose of this was to compare the chemical changes of the EVA surfaces between the glass/EVA and EVA/BS interfaces after the same DH exposure. Previous studies have shown the role of silane-based coupling agents as adhesion promoters for the glass/EVA interface [42,43], where the silane reacts with hydroxylated glass to create siloxane bonds [44]. A recent study has shown that increasing silane content increases the EVA's chemical stability against damp-heat aging [27].

Firstly, we would like to point out that independently of the backsheet used, the broad peak at $1600 \mathrm{~cm}^{-1}$ due to conjugated diene $(\mathrm{C}=\mathrm{C})$ started to broaden at the glass/EVA interface after the first DH aging tests (1) (500 h) (Figure 4a, left). Using both PET-based BSs, four noticeable new peaks on the glass/EVA interface (Figure 4a, right), and one noticeable new peak on the EVA/BS interface (Figure $4 \mathrm{~b}$, right), started to appear after $1500 \mathrm{~h} \mathrm{DH}$ aging. All of these peaks can be associated with di and tri-alkyl substance patterns as discussed earlier.

The silane agents are below the FTIR detection limits [27]. At the EVA/BS interface, without reaction to glass, the impact of silane on EVA degradation is negligible, even under $4000 \mathrm{~h}$ of damp heat aging. At the glass/EVA interface, the glass seems to act as a catalyst for EVA chemical changes demonstrated by the effect of damp heat exposure.

\subsection{Aging Comparison: Decomposition Products from FTIR-ATR}

Based on the previous results of EVA chemical changes through damp-heat aging, we further studied the influence of Vinyl Acetate (VAc) content on the combined UV/DH aging behavior of EVA, comparing with other standard tests, DH and dry-UV separately. The VAc units are more vulnerable to heat, oxygen, and UV light radiation, and therefore could easily form reactive radicals or unstable hydroperoxides and thereby facilitate further irreversible chemical reactions. EVA photo-degradation has been reported to cause a number of degradation modes: It has been demonstrated that UV irradiation plays a significant role in generating acetic acid in the presence of relative humidity, which can cause corrosion and power degradation of PV modules [45].

Quantitative results of the effects of combined UV/DH conditions (Test (3) in Table 1) are interpreted hereinafter. In comparing these results with the standard dry-UV tests (Test (2) in Table 1), we assume that the latter alone would have a minor influence on the EVA photo-degradation. During this test, the chamber's relative humidity usually accounts for $20-38 \%$. In the combined UV/DH test, however, the humidity level was set to $85 \%$ and the temperature to $60^{\circ}$, while the latter slightly increased at the sample surface due to the UV irradiation. 
After the combined UV-damp heat test of laminates with PA-based BS, the FTIR spectra of the EVA surface show a growth of a shoulder at $1715 \mathrm{~cm}^{-1}$ and a broad band at $1178 \mathrm{~cm}^{-1}$ (Figure 5). These peaks represent $\mathrm{C}=\mathrm{O}$ stretching of ketone functions. These might have formed during the acetaldehyde evolution in Norrish III reaction $[17,24]$.
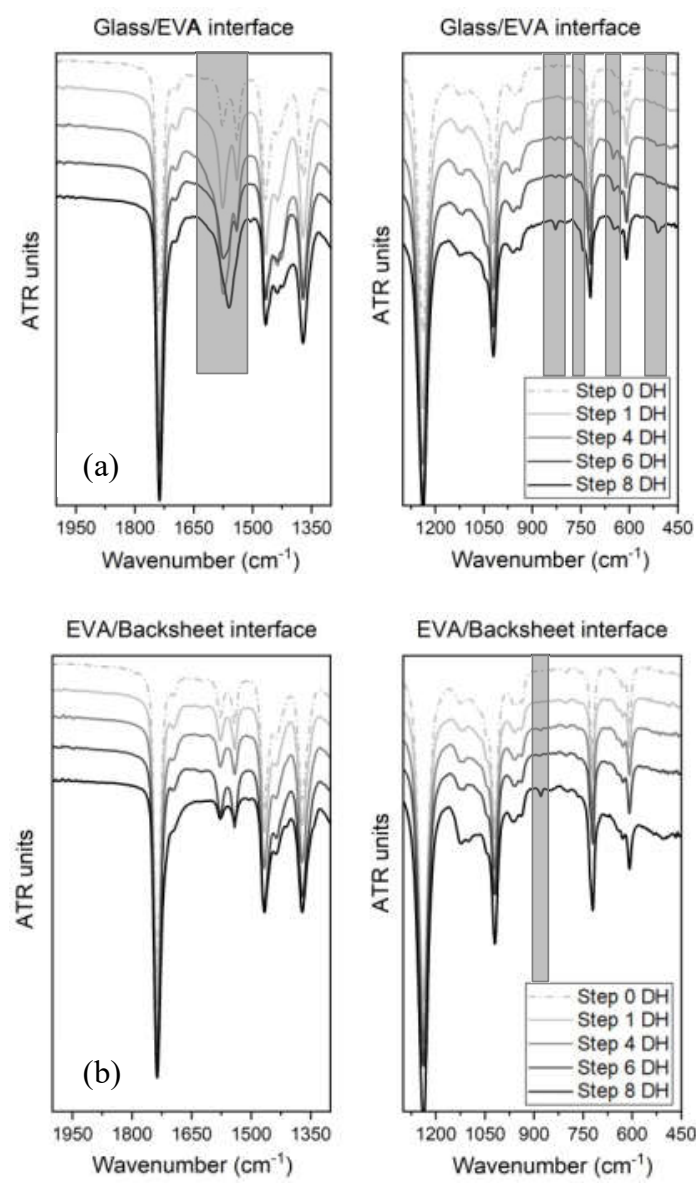

Figure 4. ATR-FTIR spectra of the EVA surface at the glass/EVA interface (a) and EVA/backsheet interface (b) before and after DH tests with PET-based BS_1. All curves are offset in the y direction for clarity.
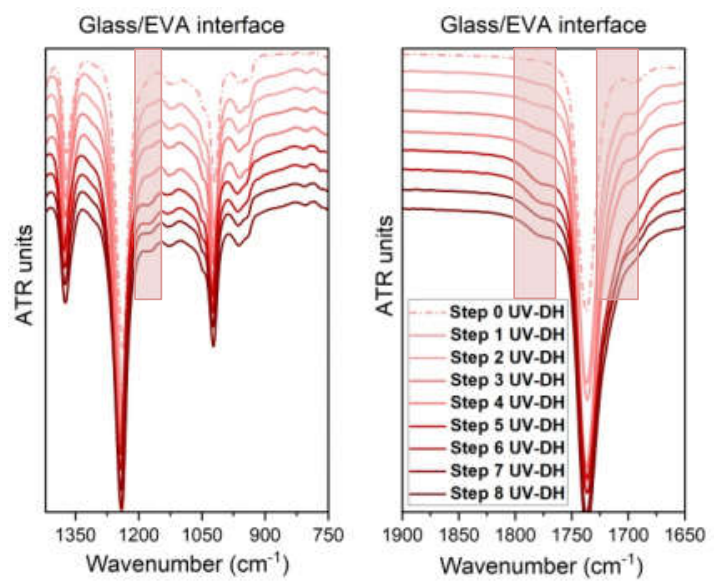

Figure 5. ATR-FTIR spectra of the EVA at glass interface before and after UV-DH combined tests with a polyamide (PA)-based backsheets (BS). All curves are offset in the y direction for clarity. 
In parallel, lactone formation was also observed through the absorption band around $1780 \mathrm{~cm}^{-1}$, indicating a back-biting process in the polymer chain $[24,46]$. These degradation products may have formed after chain-scission caused by photo-oxidation.

To obtain a quantitative comparison of specific functional groups formed during the three aging types (DH (1), UV (2) and UV-DH combined (3)), the intensity ratio between the methylene $\left(-\mathrm{CH}_{2}-\right)$ in-plane deformation rocking at $2850 \mathrm{~cm}^{-1}$ and the absorbance of the selected carbonyl, also known as the carbonyl index (CI) [20,47], were measured. As can be seen in Figure 6, $\mathrm{A}_{2850} / \mathrm{A}_{1710}$, referring to ketone formation, describes an initially small drop before growing upon further aging. Variations in $\mathrm{A}_{2850} / \mathrm{A}_{1710}$ indicate that:

- DH: No carbonyl formation from the EVA chain is observed after $4000 \mathrm{~h} \mathrm{DH}$ exposure.

- UV: Minor changes in the CI until $300 \mathrm{kWh} / \mathrm{m}^{2}$ irradiation, and then it remains stable.

- UV/DH combined: A gradual increase in the CI with longer aging and stabilization after $300 \mathrm{kWh} / \mathrm{m}^{2}$ irradiation.

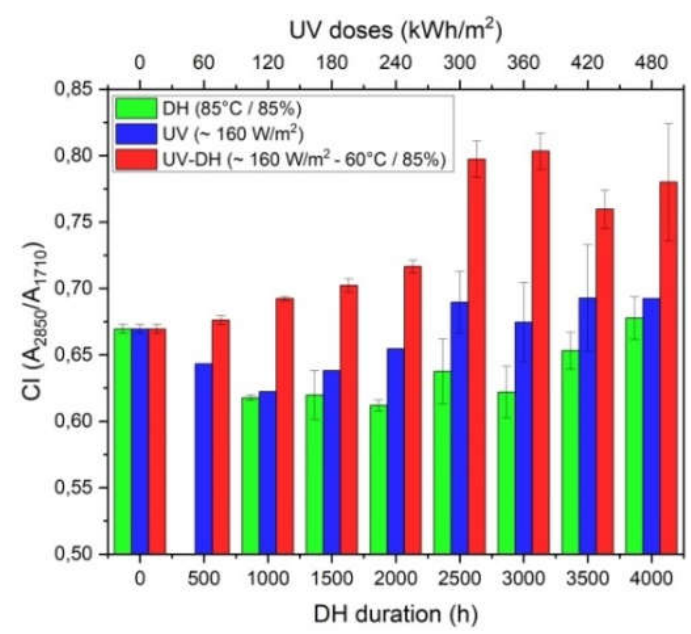

Figure 6. Carbonyl index $(\mathrm{CI})\left(\mathrm{A}_{2850} / \mathrm{A}_{1710}\right)$ of EVA with different aging tests from FTIR spectra.

Samples submitted to the combined UV/DH test showed a higher degree of carbonyl formation than those with a lower moisture exposure. We conclude that the effect of UV exposure on EVA photo-oxidation combined with high temperature is highly influenced by the moisture level. This could be due to the increase in oxygen diffusion to the EVA.

\subsection{Aging Test Comparison: Quantification of the EVA Fluorescence Background from Raman Spectra}

The Raman spectra of all aged laminates showed an intense fluorescence background which increased upon further aging (see Figure 7). The fluorescence background was correlated with the chemical degradation of the EVA. More precisely, the fluorescence intensity increased due to the formation of chromophores [12] at high Raman shift ranges for DH (green spectra), whereas dry-UV tests (spectra in blue in Figure 7) showed a maximum increase mainly between $1400 \mathrm{~cm}^{-1}$ and $2200 \mathrm{~cm}^{-1}$. Furthermore, the combination of both stress factors (combined UV/DH spectra in red in Figure 7) showed a similar behavior to the UV degradation process, albeit at a higher intensity.

These results provide evidence that DH and UV aging cause different EVA degradation processes and that the process caused by UV aging is further accelerated by the moisture present in the combined $\mathrm{UV} / \mathrm{DH}$ test to result in faster EVA photo-degradation. 


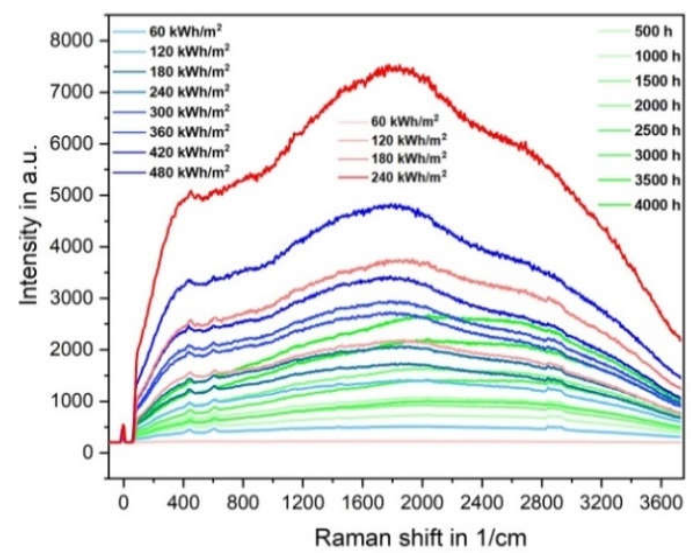

Figure 7. Raman spectra of the laminates after different aging conditions. DH tests (1) in green, UV tests (2) in blue and UV-DH tests (3) in red.

\subsection{AgingTest Comparison: Yellowness Index}

The non-destructive determination of yellowness index was used to measure the optical degradation and compare the effect of different aging tests. Figure 8 depicts a moderate discoloration of the EVA after DH test, which is in the same range as after dry-UV test (curves in green and blue). Degradation products, such as $\mathrm{C}=\mathrm{O}$ and $\mathrm{C}=\mathrm{C}$ double bonds are induced by a thermo-oxidative or photo-oxidative processes, for DH and UV, respectively [21,24]. More importantly, EVA yellowing is accelerated with a factor of 10 by combined UV-DH exposure.

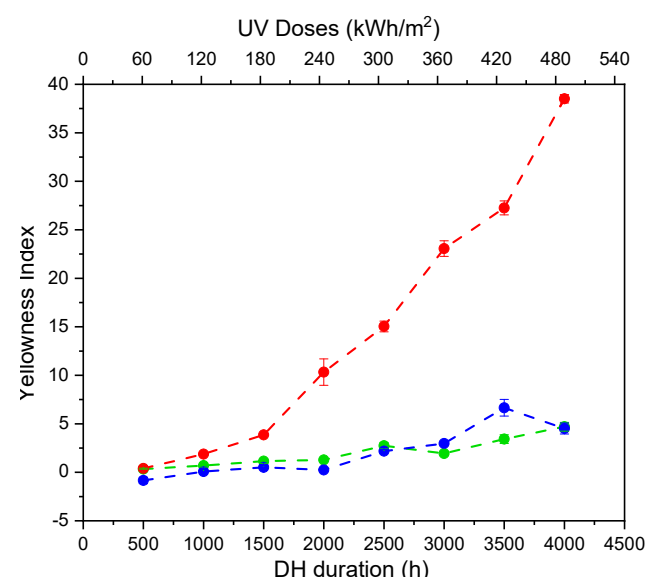

Figure 8. Yellowness index (YI) of EVA incorporated in the test laminates upon different aging condition tests. DH tests in green, UV tests in blue and UV-DH tests in red.

\subsection{Aging Comparison: Determination of EVA Melting Enthalpy}

DSC is often performed to determine differences in the crystallization of the EVA bulk. Here, we used it as a complementary technique to quantify the influence of different backsheet materials and aging stresses (summarized in Table 1) on the EVA degradation. DSC thermograms of the EVA before and after long DH (1) and UV-DH combined (3) tests are shown in Figure 9 for the example of PET-based BS_2. During the first heating cycle from 40 to $70{ }^{\circ} \mathrm{C}$, two partially overlapping endothermic peaks are observed (Figure 9a).

The peak at $45^{\circ} \mathrm{C}$ shows an increase in area after DH and combined UV-DH tests. The origin of this peak corresponds to the melting of small crystallites formed during lamination (for fresh EVA) and during the aging tests (for aged EVA) as a reversible process [29]. The position of the second peak shifts from $69^{\circ} \mathrm{C}$ to $66.5^{\circ} \mathrm{C}$ and $64^{\circ} \mathrm{C}\left(T_{m}\right)$ after DH and combined UV-DH tests, respectively, which corresponds to the melting of the ethylene segments of the EVA $[29,30,35]$. The same peak 
is also present during the second heating cycle shown in Figure $9 \mathrm{~b}$. The temperature $\left(T_{m}\right)$ of the melting peak around $67^{\circ} \mathrm{C}$ indicates a clear dependence on the aging stress. This phenomenon can be explained by the decrease in the initial molecular mass of the EVA after the different aging tests via chain-scission degradation process. The $T_{m}$ is related to the average size of the crystallites in the EVA encapsulant $[33,34,36]$.
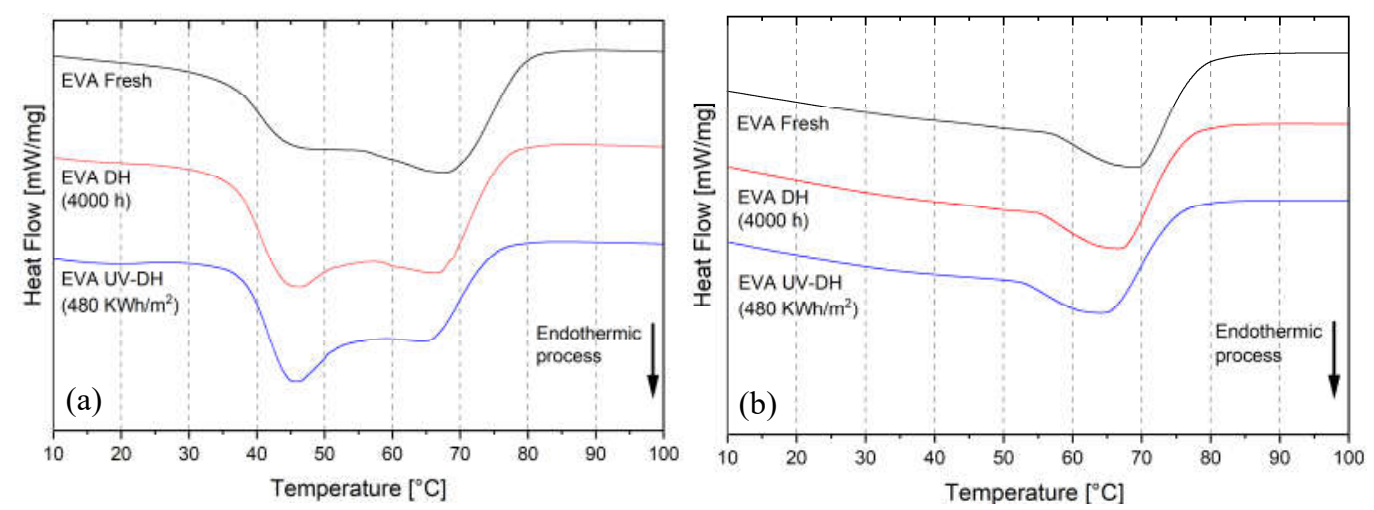

Figure 9. DSC Thermograms of EVA. (a): (First heating) two overlapped endothermic peaks are $45^{\circ} \mathrm{C}$ and $60^{\circ} \mathrm{C}$. (b): (Second heating, one remaining endothermic peak. All curves are offset in the y direction for clarity.

It has been demonstrated that the development of crystallization structures for EVA between DH and UV aging tests is different. Higher doses of UV cause faster aging than DH on crystallization of EVA as well as on the EVA/Glass adhesion strength [3]. To investigate the effect of heat dissociation in the EVA chains formed during the different aging test conditions (DH, UV-DH: using the PA-based BS. UV: using PET-based BS_1), the enthalpy of the endothermic peak during the second heating cycle was integrated and depicted in Figure 10 as a function of the different steps of aging. As the aging time increases, the enthalpy decreases and results in EVA crystals with smaller size (smaller molecular weight of EVA). Due to measurement uncertainties as indicated by error bars, it is difficult to compare between the heat dissociation rate in the EVA chains under the dry-UV (blue bars in Figure 10) and DH (green bars in Figure 10). More importantly, the experiments reveal that the chemical properties are degrading most strongly when the factors of high UV, high temperature and high relative humidity are combined (red bars in Figure 10).

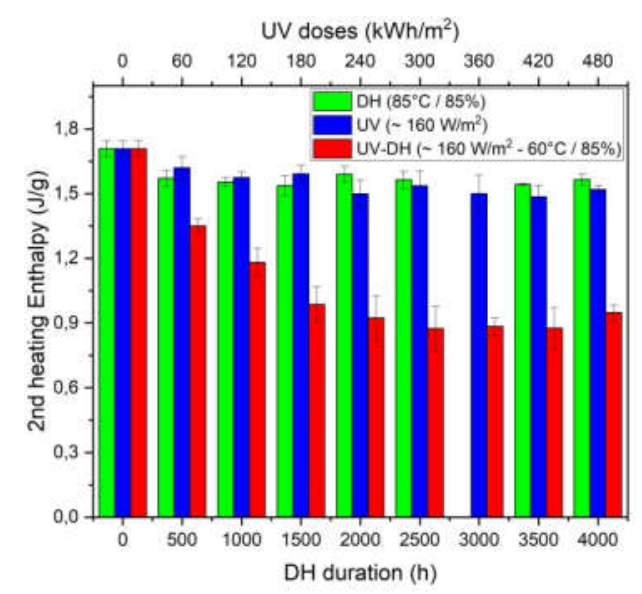

Figure 10. Evolution of the enthalpy of the endothermic transition in the DSC Thermograms of the EVA before and after different aging condition tests. 


\subsection{Backsheet Comparison: Determination of EVA Melting Enthalpy}

The decrease in the melting enthalpy is a good indicator for material/polymers degradation [32]. The enthalpy measured in the EVA decreased after the first step of $\mathrm{DH}$ aging $(500 \mathrm{~h}$ ), indicating a decrease in the average size of the crystallites of aged EVA, and then remained constant independently of the backsheet type used (Figure 11a). The enthalpies gradually decreased with the increase in UV doses in UV-DH combined tests (Figure 11b). Furthermore, only small variations were observed when PET-based backsheets were used, while stronger drops in enthalpy were observed with the PA-based backsheet. The error bars represent the standard deviation of the average enthalpies taken per aging step. The large errors after combined UV-DH tests may indicate an inhomogeneity of the EVA degradation caused by additive distribution. Thus, the results provide evidence that different material combinations (backsheet/encapsulant) lead to different degradation rates [12]. More precisely, a significant chemical degradation of EVA was observed when the PA-based backsheet was used, which is in good correlation with the results discussed earlier in the section FTIR results.
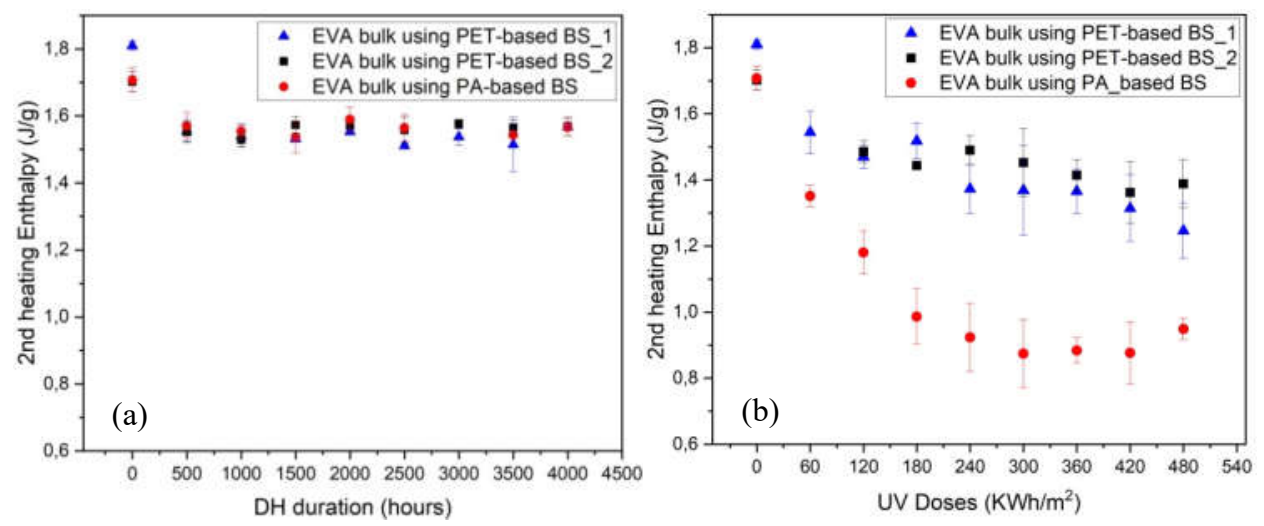

Figure 11. Evolution of the enthalpy of the endothermic transition in the DSC Thermograms of the EVA before and after DH aging (a) and UV-DH combined aging (b) (three different backsheets used in the laminates during the aging tests).

\section{Conclusions and Outlook}

This study examined the susceptibility of EVA degradation influenced by the backsheet permeation properties after performing different accelerated aging tests. The FTIR-ATR studies identified two different EVA degradation processes. A thermal oxidation was taking place in the glass-EVA-PA-based backsheet configuration after $500 \mathrm{~h}$ DH tests. However other EVA degradation products were observed in the glass-EVA-PET-based backsheet after $1500 \mathrm{~h} \mathrm{DH}$ tests. Additionally, the EVA degradation during DH was investigated at different interfaces. At the glass-EVA interface, the glass seems to act as a catalyst for EVA chemical changes of DH aging, independent of the type of backsheet used.

Furthermore, strong EVA degradation was observed when UV light, high temperature and relative humidity were combined in the aging tests. As confirmed by FTIR-ATR and Raman spectroscopies, Yellowness Index and DSC measurements, the degradation under combined UV-DH was higher than both individual stresses. The UV irradiation plays a significant role in generating photo-oxidation products which, in the presence of high moisture, cause chain-scission of EVA inside a laminate.

The next step would be to show the effect of aging on the EVA viscoelastic properties in a PV module, which are responsible for failure modes such as embrittlement, delamination, bubble formation and cell cracks. As a consequence of our findings, the change in the viscoelastic properties at the EVA surface should be more pronounced when the PA-based backsheet is used. Furthermore, a correlation between the extents of the viscoelastic damping factor $(\tan \delta)$ of EVA and the module performance, such as the power output, could also be researched. 
Author Contributions: D.E.M. lead conceptualization, methodology, software, validation, formal analysis, investigation, resources, data curation, writing - original draft preparation. C.B. contributed to conceptualization, methodology, software, data curation. L.P.B. contributed to conceptualization, methodology validation, and formal analysis. G.O. contributed to conceptualization, formal analysis, investigation, resources and supported supervision. A.S. contributed to formal analysis, investigation and supported supervision. D.P. contributed to conceptualization, funding, and supported supervision. P.G. equally contributed to conceptualization, methodology validation, formal analysis, visualization, supported supervision and writing-review and editing. All authors have read and agreed to the published version of the manuscript.

Funding: This work was supported in part by the European Union's Horizon 2020 research and innovation program in the framework of the project "SolarTrain" under the Marie Sklodowska-Curie GA 721452-H2020MSCA-ITN-2016.

Acknowledgments: The authors would like to acknowledge Georg Mülhöfer for his technical contribution with the accelerated aging tests.

Conflicts of Interest: The authors declare no conflict of interest.

\section{References}

1. Pern, F.J. Ethylene-vinyl acetate (EVA) encapsulants for photovoltaic modules: Degradation and discoloration mechanisms and formulation modifications for improved photostability. Angew. Makromol. Chem. Appl. Macromol. Chem. Phys. 1997, 252, 195-216. [CrossRef]

2. Miller, D.C.; Annigoni, E.; Ballion, A.; Bokria, J.; Bruckman, L.S.; Burns, D.M.; Chen, X.; Elliott, L.; Feng, J.; French, R.H.; et al. Degradation in PV encapsulation transmittance: An interlaboratory study towards a climate-specific test. In Proceedings of the 2015 IEEE 42nd Photovoltaic Specialist Conference (PVSC), New Orleans, LA, USA, 14-19 June 2015; pp. 1-6.

3. Wang, E.; Yang, H.E.; Yen, J.; Chi, S.; Wang, C. Failure Modes Evaluation of PV Module via Materials Degradation Approach. Energy Procedia 2013, 33, 256-264. [CrossRef]

4. Lin, C.-C.; Lyu, Y.; Jacobs, D.S.; Kim, J.H.; Wan, K.-T.; Hunston, D.L.; Gu, X. A novel test method for quantifying cracking propensity of photovoltaic backsheets after ultraviolet exposure. Prog. Photovolt. Res. Appl. 2018, 27, 44-54. [CrossRef]

5. Gebhardt, P.; Bauermann, L.P.; Philipp, D. Backsheet Chalking-Theoretical Background and Relation to Backsheet Cracking and Insulation Failures. In Proceedings of the 35th European Photovoltaic Solar Energy Conference and Exhibition, Brussels, Belgium, 24-28 September 2018.

6. Wu, D.; Zhu, J.; Betts, T.R.; Gottschalg, R. Degradation of interfacial adhesion strength within photovoltaic mini-modules during damp-heat exposure. Prog. Photovolt. Res. Appl. 2014, 22, 796-809. [CrossRef]

7. Kim, D.; Jeong, J.; Kang, B.; Kim, D. The effect of encapsulant discoloration and delamination on the electrical characteristics of photovoltaic module. Microelectron. Reliab. 2013, 53, 1818-1822. [CrossRef]

8. Tracy, J.; Bosco, N.; Novoa, F.; Dauskardt, R. Encapsulation and backsheet adhesion metrology for photovoltaic modules. Prog. Photovolt. Res. Appl. 2016, 25, 87-96. [CrossRef]

9. Köntges, M.; Kurtz, S.; Packard, C.E.; Jahn, U.; Berger, K.A.; Kato, K.; Friesen, T.; Liu, H.; Van Iseghem, M.; Wohlgemuth, J.; et al. Review of Failures of Photovoltaic Modules; Report IEA PVPS Task 13-01: Emmerthal, Germany, March 2014.

10. Köntges, M.; Oreski, G.; Jahn, U.; Hacke, P.; Weiss, K.-A.; Razongles, G.; Paggi, M.; Parlevliet, D.; Tanahashi, T.; French, R.H.; et al. Assessment of Photovoltaic Module Failures in the Field, International Energy Agency Photovoltaic Power Systems Programme; Report IEA PVPS Task 13-09: Emmerthal, Germany, May 2017.

11. Wirth, H.; Weiß, K.A.; Wiesmeier, C. Photovoltaic Modules: Technology and Reliability; Walter de Gruyter GmbH: Berlin, Germany; Boston, MA, USA, 2016; p. 223.

12. Peike, C.; Hülsmann, P.; Blüml, M.; Schmid, P.; Weiß, K.-A.; Köhl, M. Impact of Permeation Properties and Backsheet-Encapsulant Interactions on the Reliability of PV Modules. ISRN Renew. Energy 2012, 2012, 459731. [CrossRef]

13. Oreski, G.; Mihaljevic, A.; Voronko, Y.; Eder, G.C. Acetic acid permeation through photovoltaic backsheets: Influence of the composition on the permeation rate. Polym. Test. 2017, 60, 374-380. [CrossRef]

14. Voronko, Y.; Eder, G.C.; Knausz, M.; Oreski, G.; Koch, T.; Berger, K.A. Correlation of the loss in photovoltaic module performance with the ageing behaviour of the backsheets used. Prog. Photovolt. Res. Appl. 2015, 23, 1501-1515. [CrossRef] 
15. Oreski, G.; Wallner, G. Damp heat induced physical aging of PV encapsulation materials. In Proceedings of the 2010 12th IEEE Intersociety Conference on Thermal and Thermomechanical Phenomena in Electronic Systems, Las Vegas, NV, USA, 2-5 June 2010; Volume 2, pp. 1-6.

16. Ketola, B.; Norris, A. Degradation mechanism investigation of extended damp heat aged PV modules. In Proceedings of the 26th European Photovoltaic Solar Energy Conference and Exhibition, Midland, MI, USA, 5-9 September 2011.

17. Allen, N.S.; Edge, M.; Rodriguez, M.; Liauw, C.M.; Fontan, E. Aspects of the thermal oxidation, yellowing and stabilisation of ethylene vinyl acetate copolymer. Polym. Degrad. Stab. 2000, 71, 1-14. [CrossRef]

18. Czanderna, A.; Pern, F. Encapsulation of PV modules using ethylene vinyl acetate copolymer as a pottant: A critical review. Sol. Energy Mater. Sol. Cells 1996, 43, 101-181. [CrossRef]

19. Bregulla, M.; Köhl, M.; Lampe, B.; Oreski, G.; Philipp, D.; Wallner, G.; Weiß, K.A. Degradation mechanisms of ethylene vinyl acetate copolymer: New studies including ultra fast cure foils. In Proceedings of the 22nd European Photovoltaic Solar Energy Conference, Milan, Italy, 3-7 September 2007.

20. Rodriguez-Vazquez, M.; Liauw, C.; Allen, N.S.; Edge, M.; Fontan, E. Degradation and stabilisation of poly(ethylene-stat-vinyl acetate): 1-Spectroscopic and rheological examination of thermal and thermo-oxidative degradation mechanisms. Polym. Degrad. Stab. 2006, 91, 154-164. [CrossRef]

21. Oreski, G.; Wallner, G. Evaluation of the aging behavior of ethylene copolymer films for solar applications under accelerated weathering conditions. Sol. Energy 2009, 83, 1040-1047. [CrossRef]

22. Segal, E.; Budrugeac, P.; Ciutacu, S.; Mares, G. On the change in the thermal behaviour of the compound eva owing to accelerated thermal and radiation-induced ageing. Thermochim. Acta 1990, 164, 161-169. [CrossRef]

23. Na Ayutthaya, S.I.; Wootthikanokkhan, J. Investigation of the photodegradation behaviors of an ethylene/vinyl acetate copolymer solar cell encapsulant and effects of antioxidants on the photostability of the material. J. Appl. Polym. Sci. 2007, 107, 3853-3863. [CrossRef]

24. Jin, J.; Chen, S.; Zhang, J. UV aging behaviour of ethylene-vinyl acetate copolymers (EVA) with different vinyl acetate contents. Polym. Degrad. Stab. 2010, 95, 725-732. [CrossRef]

25. Ottersböck, B.; Oreski, G.; Pinter, G. Comparison of different microclimate effects on the aging behavior of encapsulation materials used in photovoltaic modules. Polym. Degrad. Stab. 2017, 138, 182-191. [CrossRef]

26. Hacke, P.; Owen-Bellini, M.; Kempe, M.; Miller, D.C.; Tanahashi, T.; Sakurai, K.; Gambogi, W.J.; Trout, J.T.; Felder, T.C.; Choudhury, K.R.; et al. Combined and Sequential Accelerated Stress Testing for Derisking Photovoltaic Modules. In Advanced Micro- and Nanomaterials for Photovoltaics; Elsevier BV: Amsterdam, The Netherlands, 2019; pp. 279-313.

27. Spinella, L.; Bosco, N. FTIR Investigation of EVA Chemical Bonding Environment and Its Impact on Debond Energy. IEEE J. Photovolt. 2019, 9, 790-795. [CrossRef]

28. Peike, C.; Phondongnok, W.; Kaltenbach, T.; Weiss, K.-A.; Koehl, M. Non-destructive determination of the cross-linking degree of EVA by Raman Spectroscopy. Open J. Renew. Energy Sustain. Dev. 2014, 2014, 14-21. [CrossRef]

29. Agroui, K.; Maallemi, A.; Boumaour, M.; Collins, G.; Salama, M. Thermal stability of slow and fast cure EVA encapsulant material for photovoltaic module manufacturing process. Sol. Energy Mater. Sol. Cells 2006, 90, 2509-2514. [CrossRef]

30. Stark, W.; Jaunich, M. Investigation of Ethylene/Vinyl Acetate Copolymer (EVA) by thermal analysis DSC and DMA. Polym. Test. 2011, 30, 236-242. [CrossRef]

31. Chapuis, V.; Pélisset, S.; Raeis-Barnéoud, M.; Li, H.-Y.; Ballif, C.; Perret-Aebi, L.-E. Compressive-shear adhesion characterization of polyvinyl-butyral and ethylene-vinyl acetate at different curing times before and after exposure to damp-heat conditions. Prog. Photovolt. Res. Appl. 2012, 22, 405-414. [CrossRef]

32. Patel, A.P.; Sinha, A.; Tamizhmani, G. Field-Aged Glass/Backsheet and Glass/Glass PV Modules: Encapsulant Degradation Comparison. IEEE J. Photovolt. 2020, 10, 607-615. [CrossRef]

33. Motta, C. The effect of copolymerization on transition temperatures of polymeric materials. J. Therm. Anal. Calorim. 1997, 49, 461-464. [CrossRef]

34. Somrang, N.; Nithitanakul, M.; Grady, B.P.; Supaphol, P. Non-isothermal melt crystallization kinetics for ethylene-acrylic acid copolymers and ethylene-methyl acrylate-acrylic acid terpolymers. Eur. Polym. J. 2004, 40, 829-838. [CrossRef]

35. Kempe, M.D. Rheological and mechanical considerations for photovoltaic encapsulants. In Proceedings of the 2005 DOE Solar Energy Technologies Program Review Meeting, Golden, CO, USA, 1 November 2005. 
36. Li, H.-Y.; Perret-Aebi, L.-E.; Théron, R.; Ballif, C.; Luo, Y.; Lange, R.F.M. Optical transmission as a fast and non-destructive tool for determination of ethylene-co-vinyl acetate curing state in photovoltaic modules. Prog. Photovolt. Res. Appl. 2011, 21, 187-194. [CrossRef]

37. Bistac, S.; Kunemann, P.; Schultz, J. Crystalline modifications of ethylene-vinyl acetate copolymers induced by a tensile drawing: Effect of the molecular weight. Polymer 1998, 39, 4875-4881. [CrossRef]

38. International Electrotechnical Commission (IEC). Terrestrial Photovoltaic (PV) Modules-Design Qualification and Type Approval-Part 2: Test Procedures; International Electrotechnical Commission (IEC): Geneva, Switzerland, 2016.

39. Sultan, B.-Å.; Sörvik, E. Thermal degradation of EVA and EBA-A comparison. III. Molecular weight changes. J. Appl. Polym. Sci. 1991, 43, 1761-1771. [CrossRef]

40. Sultan, B.-Å.; Sörvik, E. Thermal degradation of EVA and EBA-A comparison. I. Volatile decomposition products. J. Appl. Polym. Sci. 1991, 43, 1737-1745. [CrossRef]

41. Sultan, B.-Å.; Sörvik, E. Thermal degradation of EVA and EBA-A comparison. II. Changes in unsaturation and side group structure. J. Appl. Polym. Sci. 1991, 43, 1747-1759. [CrossRef]

42. Plueddemann, E.P. Silane Coupling Agents; Springer: Boston, MA, USA, 1991.

43. Arkles, B. Silane Coupling Agents: Connecting Across Boundaries; Gelest Inc.: Morrisville, PA, USA, 2014.

44. Coulter, D.R.; Cuddihy, E.F.; Plueddeman, E.P. Chemical bonding technology for terrestrial photovoltaic modules. STIN 1983, 84, 22008.

45. Ngo, T.; Heta, Y.; Doi, T.; Masuda, A. Effects of UV on power degradation of photovoltaic modules in combined acceleration tests. Jpn. J. Appl. Phys. 2016, 55, 52301. [CrossRef]

46. Allen, N.S.; Edge, M.; Mohammadian, M.; Jones, K. Physicochemical aspects of the environmental degradation of poly(ethylene terephthalate). Polym. Degrad. Stab. 1994, 43, 229-237. [CrossRef]

47. Abdel-Bary, E.M.; Abdel-Razik, E.A.; Abdelaal, M.; El-Sherbiny, I.M. Stability of Polypropylene Blends Under the Effect of Thermal and UV Degradation. Polym. Technol. Eng. 2005, 44, 847-862. [CrossRef]

(C) 2020 by the authors. Licensee MDPI, Basel, Switzerland. This article is an open access article distributed under the terms and conditions of the Creative Commons Attribution (CC BY) license (http://creativecommons.org/licenses/by/4.0/). 